\title{
Protección pensional a las personas sin ingresos: un mandato constitucional ${ }^{* *}$
}

\section{Pension protection for those without an income: A constitutional mandate in Colombia}

RESUMEN

Esta monografía identifica las características específicas del modelo pensional colombiano que permiten comprobar su incongruencia con las disposiciones constitucionales vigentes, en especial las relativas al derecho a la pensión como derecho económico, social y cultural. Por lo anterior, se propone la adopción de pilares no contributivos y la eliminación de subsidios a la población con ingresos, como un paso en la corrección de los problemas actuales del Sistema General de Pensiones.

PALABRAS CLAVE

Pensiones, derechos económicos y sociales (DESC), pensiones no contributivas, vejez, indefensión, seguridad social, regresividad, progresividad, desigualdad, subsidios.

\section{ABSTRACT}

This paper identifies the specific characteristics of the Colombian pension model that demonstrate its incongruence with to the constitutional rules set out for the right to pension considered as an economic, social and cultural right. Therefore, the establishment of non-contributory pillars and the elimi-

* Abogado de la Universidad EAfIT. Especialista en Economía y Magister en Derecho de la Universidad de los Andes. Consultor en asuntos de seguridad social, derecho económico y justicia. Actualmente asesor de la Secretaría Jurídica de la Presidencia de la República. Contacto: alejobotero@gmail.com

** Texto de la monografía de grado para acceder al título de Magister en Derecho de la Universidad de los Andes. Julio de 2015.

Recibido el 27 de julio de 2016, aprobado el 1. ${ }^{\circ}$ de octubre de 2016.

Para citar el artículo: A. Botero VALENCIA. Protección pensional a las personas sin ingresos: un mandato constitucional. Derecho del Estado n. ${ }^{\circ} 37$, Universidad Externado de Colombia, julio-diciembre de 2016, pp. 69-94. Dor: http://dx.doi.org/10.18601/01229893.n37.02 
nation of subsidies to the population with incomes are proposed as a step in correcting the current problems of the General Pension System.

KEYWORDS

Pensions, ESCR, non-contributory pensions, old age, helplessness, social security, regressivity, progressivity, inequality, subsidies.

SUMARIO

Introducción. I. El derecho a la pensión como derecho económico y social. Jurisprudencia constitucional y normativa interamericana. i. Los principios de progresividad y no regresividad en la jurisprudencia constitucional. ii. El derecho a la pensión en el Sistema Interamericano de Derechos Humanos. II. Las pensiones estancadas: el modelo legal y la jurisprudencia constitucional. i. El modelo legal del sistema de pensiones: protección contributiva y distribución regresiva. ii. La jurisprudencia constitucional sobre el derecho a la pensión en sede de constitucionalidad. III. Los problemas constitucionales del sistema de pensiones. i. La pensión como derecho no contributivo. ii. Una regulación adecuada del derecho a la pensión de vejez.

\section{INTRODUCCIÓN}

El derecho a la pensión ha sido reconocido por la Constitución Política y por los tratados internacionales sobre derechos humanos ratificados por Colombia, como un derecho económico, social y cultural (DESC). Dicho reconocimiento implica que las disposiciones legales que regulen el derecho a la pensión deben sujetarse a los principios de progresividad y no regresividad, los cuales demandan un reconocimiento universal de este derecho, pero de forma progresiva, priorizando la ejecución de los recursos escasos disponibles en la población que más lo requiera.

En este sentido, sólo en la medida que se logra la cobertura mínima, en términos de población objetivo o de beneficios otorgados, es posible cubrir a otros grupos poblacionales que continúen en el orden de priorización establecido, siempre que se cuente con los recursos necesarios y bajo la condición de no retroceder en los niveles de cobertura logrados.

A pesar de lo anterior, la regulación legal en Colombia no protege el derecho a la pensión como un DESC, por lo menos por dos razones: (i) no cubre a la población con ingresos inferiores a un salario mínimo, excluyendo a los grupos que más requieren protección -como las personas de la tercera edad en estado de indigencia-, y (ii) destina los recursos públicos escasos, que deberían dirigirse a la población "priorizada", a financiar parcialmente 
las pensiones de las personas con ingresos iguales o superiores a un salario mínimo mensual en el Régimen de Prima Media.

Este desconocimiento legal de la naturaleza del derecho a la pensión ha sido además avalado tácitamente por la Corte Constitucional, la cual ha mantenido una concepción del mismo como un derecho exclusivamente contributivo, al no reconocer los mandatos que se desprenden directamente del texto constitucional y de tratados internacionales sobre derechos humanos ratificados por Colombia, los cuales hacen parte del bloque de constitucionalidad.

Teniendo en cuenta lo anterior, el presente trabajo busca identificar las características específicas del sistema pensional que implican su incongruencia con los mandatos constitucionales mencionados, revisar la jurisprudencia que avala este modelo legal y proponer cambios concretos al mismo para avanzar en la solución de los problemas identificados.

El documento se divide en tres partes: (i) una breve explicación de los principios de los DESC -relevantes para los argumentos que se sostienen- a partir de la jurisprudencia constitucional y los tratados internacionales sobre la materia; (ii) la revisión del modelo legal y de la jurisprudencia constitucional sobre el sistema de protección al derecho a la pensión adoptado desde la Ley 100 de 1993, y (iii) la explicación de los problemas constitucionales que presenta el actual modelo de pensiones como resultado de la negación tácita que el legislador y la Corte Constitucional realizan de las características del derecho a la pensión como DESC, para terminar con algunas propuestas dirigidas a corregir esta situación.

\section{EL DERECHO A LA PENSIÓN COMO DERECHO ECONÓMICO Y SOCIAL. JURISPRUDENCIA CONSTITUCIONAL Y NORMATIVA INTERAMERICANA}

En esta sección se explican las consecuencias jurídicas de que el derecho a la pensión haya sido clasificado y considerado por la Constitución y los tratados internacionales como DESC. Específicamente, a partir de la jurisprudencia constitucional y de algunos de los tratados internacionales sobre derechos humanos ratificados por Colombia, se intenta demostrar que el derecho a la pensión, como DESC, analizado desde la perspectiva de los principios de progresividad y no regresividad que rigen este tipo de derechos, implica proteger con pensiones no contributivas ${ }^{1}$ a la población más vulnerable.

1 Se entiende por pensiones no contributivas el reconocimiento del derecho a una mesada pensional periódica, irrevocable y actualizable, a personas que por sus condiciones económicas, de salud y de edad no pudieron cotizar lo suficiente al Sistema General de Pensiones durante su vida laboral para obtener una pensión financiada con sus propios aportes. Estas pensiones deben ser inferiores al salario mínimo, no sólo por el costo fiscal de las mismas, sino también por la necesidad de establecer incentivos para que las personas que puedan cotizar no dejen de hacerlo por el hecho de que exista la posibilidad de obtener una pensión en un régimen subsidiado o no contributivo. 


\section{i. Los principios de progresividad y no regresividad en la jurisprudencia constitucional}

Entre las diferentes categorías de derechos, en Colombia se tiende a reconocer con facilidad aquellos que gozan de la característica de ser fundamentales, pues gracias a la acción de tutela -a su eficacia, eficiencia, sencillez, disponibilidad y oportunidad- casi cualquier colombiano está en capacidad de señalar cuándo uno de sus derechos fundamentales está siendo vulnerado. Por el contrario, en el caso de los DESC resulta más difícil reconocer la naturaleza de cada derecho, su alcance y las formas de protección, pues al no gozar de las mismas características de inmediatez y exigibilidad de los derechos fundamentales, no pueden ser defendidos siempre vía acción de tutela.

A pesar de lo anterior, los DESC cuentan con una consagración formal, a nivel del ordenamiento constitucional interno y del derecho internacional de los derechos humanos, y con mecanismos materiales para su protección, es decir, son exigibles y fácilmente identificables. Pero, a diferencia de los derechos fundamentales y dadas sus características, el nivel de exigibilidad de los DESC es limitado, característica que puede explicarse a partir de dos de los principios que los rigen: la progresividad y la prohibición de regresividad.

Normalmente, estos dos principios que rigen los DESC suelen ser comprendidos y explicados en la jurisprudencia constitucional colombiana como una misma cuestión:

El mandato de progresividad implica que una vez alcanzado un determinado nivel de protección, la amplia libertad de configuración del legislador en materia de derechos sociales se ve restringida, al menos en un aspecto: todo retroceso frente al nivel de protección alcanzado es constitucionalmente problemático puesto que precisamente contradice el mandato de progresividad (Corte Constitucional, Sentencia C-038 de 2004).

A pesar de que existe una estrecha relación entre ambos principios, lo cierto es que son independientes, pues mientras el de progresividad implica un mandato para el Estado en el sentido de avanzar paulatinamente en la protección de los derechos de acuerdo con los recursos escasos disponibles, el de no regresividad prohíbe retrocesos en cuanto a los niveles de protección alcanzados. Aunque la interrelación entre ambos principios es evidente, el desarrollo de sus características particulares resalta su independencia, como se expone a continuación.

Por una parte, el principio de progresividad implica que al Estado no puede exigírsele la garantía total o universal de un determinado DESC, pues su aplicación generalizada depende de la disponibilidad de recursos, de la priorización en las políticas públicas, de las necesidades sociales más inmediatas, entre otras cosas. Sin embargo, no significa lo anterior que el Estado pueda 
escudarse en este principio para justificar la ausencia de avances en materia de garantía de los DESC. Así lo ha puesto de manifiesto la Corte Constitucional en innumerables ocasiones, indicando que "el mandato de progresividad no debe ser entendido como una justificación de la inactividad del Estado en la protección de esos derechos" (Corte Constitucional, Sentencia C-671 de 2002) y que, en su lugar, aunque los DESC no sean de aplicación inmediata, el Estado debe procurar por su reconocimiento universal, ejecutando todas las acciones que estén a su alcance para avanzar en la protección progresiva de los mismos.

Adicionalmente, el principio de progresividad implica un mandato lógico: toda política pública en materia de desarrollo de DESC debe empezar protegiendo a la población más vulnerable. En otras palabras, el principio de progresividad implica empezar desde abajo, en términos de cubrimiento y población objetivo, por lo que es un mandato de priorización.

Aceptadas las dos consecuencias anteriores tendríamos que, en cumplimiento de la garantía progresiva de los DESC, el Estado está obligado a ejecutar en todo momento las acciones posibles tendientes al cubrimiento progresivo de estos derechos, las cuales deben realizarse "desde abajo", es decir, priorizando siempre a los sectores poblacionales más necesitados.

Así, las obligaciones positivas del Estado, enmarcadas principalmente en los DESC, deben tender en primer lugar a eliminar las condiciones de desigualdad entre la población, especialmente cuando las soluciones planteadas por el legislador representan obligaciones del Presupuesto Público Nacional. Este mandato se desprende de la aplicación del principio de igualdad material, el cual exige una lectura más amplia del principio de progresividad en la garantía de los derechos sociales y del cual se deriva el mandato de priorización del gasto público social ${ }^{2}$.

Todas estas consecuencias que se han extraído del principio de progresividad implican que hay un nivel mínimo de protección de cada DESC que el Estado tiene la obligación de proteger. La Corte Constitucional, en una de las primeras sentencias en que se ocupó ampliamente de la naturaleza y exigibilidad de los DESC, identificó este nivel mínimo de protección como el "contenido esencial" de estos derechos al plantear:

El deber de realización progresiva de los derechos sociales prestacionales no significa que no pueda haber violación de los mismos, debido a omisiones del

2 Por ejemplo, en la Sentencia T-441 de 2006, la Corte afirma: "La superación de un modelo de simple igualdad formal, en la cual el aparato estatal reconoce a los individuos como titulares de análogos derechos y deberes, a uno de igualdad material, que advierte la necesidad de promover la equiparación de oportunidades a través de la disposición de tratamientos diferenciados positivos, explica en buena medida qué criterio debe imperar en un Estado constitucional para la distribución de bienes públicos escasos". 
Estado o a actuaciones insuficientes de su parte. En efecto, así como existe un contenido esencial de los derechos civiles y políticos, la doctrina internacional considera que existe un contenido esencial de los derechos económicos y sociales, el cual se materializa en los "derechos mínimos de subsistencia para todos, sea cual fuere el nivel de desarrollo económico".

Por ende, se considera que existe una violación a las obligaciones internacionales si los Estados no aseguran ese mínimo vital, salvo que existan poderosas razones que justifiquen la situación. Además, el Estado adquiere el compromiso de tomar "todas las medidas que sean necesarias, y, hasta el máximo de los recursos disponibles", por lo cual, si se constata que los recursos no han sido adecuadamente utilizados para la realización de estos derechos, también se puede considerar que el Estado está incumpliendo sus obligaciones internacionales (Corte Constitucional, Sentencia C-251 de 1997).

Por otra parte, el principio de no regresividad establece una prohibición relativa para el Estado, en el sentido de restringir cualquier medida que disminuya un determinado nivel de satisfacción de los DESC, la cual se entenderá prima facie como una medida contraria a la Constitución (Corte Constitucional, Sentencia C-438 de 2013). De acuerdo con la Corte Constitucional, existen varios eventos en los que determinada medida puede entenderse como regresiva: “(1) cuando recorta o limita el ámbito sustantivo de protección del respectivo derecho; (2) cuando aumenta sustancialmente los requisitos exigidos para acceder al respectivo derecho; (3) cuando disminuye o desvía sensiblemente los recursos públicos destinados a la satisfacción del derecho" (Corte Constitucional, Sentencia C-507 de 2008).

Es decir, mientras el principio de progresividad implica priorización, garantías mínimas de los DESC y avances en su protección, el principio de no regresividad impone al Estado una obligación correlativa pero diferente, en el sentido de garantizar que los niveles de protección alcanzados no serán desmejorados.

Los DESC no son pues simples llamados al desarrollo de políticas públicas. Son derechos cuya exigibilidad absoluta no es inmediata, pues su realización depende, antes que de la voluntad política, de la disponibilidad de recursos y de las necesidades sociales, y sin embargo existen niveles de exigibilidad mínimos y mecanismos para que esta pueda darse: la acción de tutela, la acción de inconstitucionalidad, las acciones populares, los mecanismos administrativos -como el derecho de petición y los recursos de la vía gubernativa-, y los recursos ante las instancias internacionales. Estos niveles mínimos y mecanismos de exigibilidad implican también que, sin importar las formas de desarrollo legal y protección administrativa de un determinado DESC, es posible exigir su protección para los grupos más 
vulnerables de la población, de acuerdo con la aplicación igualitaria del principio de progresividad ${ }^{3}$.

\section{ii. El derecho a la pensión en el Sistema Interamericano de Derechos Humanos}

La jurisprudencia constitucional es precisa en identificar la importancia de los principios de progresividad y no regresividad en el desarrollo de los DESC, especialmente en cuanto a las implicaciones restrictivas que para la configuración legal de dichos derechos tienen los mencionados principios. Estas mismas consecuencias, que delimitan el ámbito de configuración de los DESC, pueden ser explicadas a partir de los tratados internacionales sobre derechos humanos ratificados por Colombia, específicamente para el caso del derecho a la pensión como DESC.

Aunque es posible identificar importantes desarrollos del derecho a la pensión de vejez en diversos instrumentos de carácter internacional ratificados por Colombia ${ }^{4}$, nos centraremos en el desarrollo que el mismo ha tenido en el Sistema Interamericano de Derechos Humanos (SIDH) ${ }^{5}$. Lo anterior, puesto que es este el sistema internacional de carácter regional al que Colombia se encuentra directamente vinculado, y en cuanto en el mismo pueden identificarse definiciones sobre los DESC en general y sobre el derecho a la pensión en particular que permiten explicar las obligaciones del Estado colombiano en el desarrollo de este derecho.

Así, entre los instrumentos internacionales aplicables al sIDH se encuentra la Convención Americana sobre Derechos Humanos (CADH), la cual contiene una cláusula general de protección de los DESC en su artículo $26^{[6]}$, que com-

3 A una conclusión similar llega Castillo Cadena al afirmar: "La Constitución Política privilegia la cobertura universal en relación con la cobertura por nivel del servicio. La acción estatal, incluida la judicial, debiera estar dirigida a lograr y garantizar la cobertura universal de la seguridad social, mediante un derecho de mínimos. A partir del momento en que se logre dicha cobertura se podría pensar en ampliar los servicios, o mejor, desarrollar cabalmente el principio de integralidad" (2006, p. 143).

4 Por ejemplo, la Declaración Universal de Derechos Humanos establece la obligación de los Estados de reconocer progresivamente los DESC y, específicamente, el derecho de toda persona a la seguridad social (art. 22) y al seguro por riesgos de invalidez, viudez o vejez (art. 25); mientras que el Pacto Internacional de Derechos Económicos, Sociales y Culturales reconoce el derecho de toda persona a la seguridad social (art. 9).

5 Convención Americana sobre Derechos Humanos (CADH), Carta de la oEA y Protocolo Adicional a la CADH sobre Derechos Económicos, Sociales y Culturales.

6 "Los Estados Partes se comprometen a adoptar providencias, tanto a nivel interno como mediante la cooperación internacional, especialmente económica y técnica, para lograr progresivamente la plena efectividad de los derechos que se derivan de las normas económicas, sociales y sobre educación, ciencia y cultura, contenidas en la Carta de la Organización de los Estados Americanos, reformada por el Protocolo de Buenos Aires, en la medida de los recursos disponibles, por vía legislativa u otros medios apropiados". 
promete a los Estados parte a adelantar acciones tendientes al logro progresivo de los "derechos que se derivan de las normas económicas, sociales y sobre educación, ciencia y cultura, contenidas en la Carta de la Organización de los Estados Americanos".

Por su parte, la Carta de la oEA, a la que hace referencia el artículo citado, no contiene referencias ni listados específicos sobre los DESC, pero incluye un capítulo sobre "Desarrollo Integral", dirigido a comprometer a los Estados en el desarrollo integral de sus pueblos en "los campos económico, social, educacional, cultural, científico y tecnológico", y que hace una referencia general a la seguridad social y a la protección a la vejez.

Por otra parte, como instrumento adicional del siDH, en 1988 se firmó el Protocolo Adicional a la CADH sobre Derechos Económicos, Sociales y Culturales, conocido como el Protocolo de San Salvador (PSS). De acuerdo con Romero, la creación de este instrumento implica un reconocimiento de los DESC como derechos en el ámbito internacional, por oposición a su simple concepción como políticas estatales ${ }^{7}$ (2013, p. 10).

Específicamente respecto del derecho a la pensión, el artículo 9 del Pacto define el derecho a la seguridad social como el derecho de toda persona a ser protegida "contra las consecuencias de la vejez y de la incapacidad que la imposibilite física o mentalmente para obtener los medios para llevar una vida digna y decorosa". Así, en este artículo se establece el derecho a las pensiones de vejez, invalidez y muerte, determinando que el mismo hace parte de la categoría más general del derecho a la seguridad social. Adicionalmente, en un numeral independiente, establece el derecho que tienen los trabajadores a la jubilación, entendida como la pensión a la que tiene derecho un trabajador cuando exista invalidez por causas laborales ${ }^{8}$.

Por otra parte, el artículo siguiente del Pss consagra de manera separada el derecho a la salud, con lo cual se establece una caracterización independiente de este derecho, comprendido normalmente dentro del género de la seguridad social. Igualmente, el derecho al trabajo es consagrado y definido de forma independiente respecto del derecho a la seguridad social en general y del derecho a la pensión en particular.

7 Indica la autora citada que el PSS "representó el punto culminante de una toma de conciencia, global y regional, a favor del reconocimiento internacional de los DESC: se reconoce que ya no podían ser entendidos como simples objetos de la acción política de los Estados. El PSS surge entonces del intento de remediar las deficiencias de los DESC en el SIDH, reforzando su protección".

8 La "jubilación” a la que se refiere el Pacto en este caso, se refiere a la actual pensión de invalidez por accidentes de trabajo del Régimen General de Riesgos Laborales: "Cuando se trate de personas que se encuentran trabajando, el derecho a la seguridad social cubrirá al menos la atención médica y el subsidio o jubilación en casos de accidentes de trabajo o de enfermedad profesional y, cuando se trate de mujeres, licencia retribuida por maternidad antes y después del parto". 
Adicionalmente, el artículo 17 Pss, "Protección a los ancianos", establece el derecho a la protección estatal a favor de las personas de la tercera edad o, como indica el mismo pacto, "durante su ancianidad", diferenciando entre el derecho a la pensión o protección contra lo efectos de la vejez, y el derecho de protección especial de que deben ser objeto las personas de la tercera edad -en asuntos como la garantía de vivienda, alimentación e inclusive condiciones de ocupación dignas-.

En conclusión, desde el punto de vista positivo, existe una consagración normativa internacional del derecho a la pensión de vejez, específicamente como DESC, que obliga al Estado a reconocerlo progresivamente, priorizando su garantía de acuerdo con los principios de progresividad y de prohibición de regresividad, los cuales se desprenden de los mismos instrumentos internacionales sobre derechos humanos ratificados por Colombia.

Estas provisiones sobre derechos humanos ratificadas por Colombia, como se anunció en la introducción, hacen parte del bloque de constitucionalidad ${ }^{9}$, por lo que no sólo pertenecen al ordenamiento jurídico interno, sino que prevalecen sobre las normas legales al ser criterio de control de constitucionalidad. Por ello, son límites a la acción legislativa, que debe sujetarse a los mismos para el desarrollo de las políticas públicas sobre DESC, aplicando los mandatos constitucionales que se desprenden de principios como la progresividad y la prohibición de regresividad.

\section{LAS PENSIONES ESTANCADAS: EL MODELO LEGAL Y LA JURISPRUDENCIA CONSTITUCIONAL}

Teniendo en cuenta las conclusiones de la sección anterior, que a partir de la jurisprudencia y los tratados internacionales resalta las características

9 "El bloque de constitucionalidad incluye normas que sin figurar formalmente en el texto constitucional, son utilizadas como parámetros de control de constitucionalidad al tener jerarquía constitucional por remisión directa de la Constitución (artículo 93). Ellas son (i) los tratados internacionales que reconocen derechos humanos, y las del derecho internacional humanitario, bloque de constitucionalidad stricto sensu; y, (ii) aunque no tengan rango constitucional configuran parámetros para examinar la validez constitucional de las normas sujetas a control las leyes estatutarias, las leyes orgánicas y algunos convenios internacionales de derechos humanos, calificados como integrantes del bloque de constitucionalidad lato sensu" (Corte Constitucional, Sentencia C-664 de 2013). "La Corte Constitucional ha expresado que la seguridad social es un derecho fundamental cuyo desarrollo, aunque ha sido confiado a entidades específicas que participan en el sistema general de seguridad social, tiene una configuración normativa ya establecida, tanto en el texto constitucional, como en los tratados internacionales que hacen parte del bloque de constitucionalidad, los cuales dan cuenta de una categoría iusfundamental arraigada al derecho fundamental de la dignidad humana [...] El derecho a la seguridad social se encuentra consagrado en diversos instrumentos de carácter internacional sobre Derechos Humanos, ratificados por Colombia, razón por la cual al pertenecer al bloque de constitucionalidad, evidentemente hacen parte del ordenamiento interno colombiano, tal como se establece en el artículo 93 de la Carta" (Corte Constitucional, Sentencia T-588 de 2014). 
principales de los DESC en general y del derecho a la pensión en particular, a continuación entramos a revisar el desarrollo legal y jurisprudencial del derecho a la pensión que en dicho marco constitucional se ha realizado en Colombia.

\section{i. El modelo legal del sistema de pensiones: protección contributiva y distribución regresiva}

El sistema pensional anterior a la Ley 100 de 1993 estaba constituido por un innumerable conjunto de actores: cajas de previsión social que representaban entidades públicas o sectores; empleadores privados encargados de sus propios pensionados; entidades territoriales y nacionales con pensiones a su cargo, y el Instituto de los Seguros Sociales (ISs), que agrupaba algunos servidores públicos y trabajadores privados. De igual forma, la normativa que regía las relaciones entre dichos actores y entre los mismos y los trabajadores era diversa en su naturaleza y contenido: pactos y convenciones colectivas; leyes dirigidas a grupos particulares; decretos legislativos e incluso reglamentarios con reglas y regímenes especiales, y normas territoriales aplicables especialmente a funcionarios públicos ${ }^{10}$.

Este modelo disperso de actores y normas, que resultaba caótico, insostenible e incontrolable ${ }^{11}$, se asociaba exclusivamente con la protección pensional del trabajador, es decir, desde el inicio se pensó como un sistema dependiente, de forma exclusiva, del mercado de trabajo formal. Por ello, no podía considerarse como un sistema pensional propiamente dicho, pues carecía de pretensión de universalidad y se trataba más bien de la regulación legal de las relaciones laborales de largo plazo.

Como respuesta a esta situación y a los nuevos mandatos constitucionales de 1991, el sistema de pensiones construido por el legislador desde la Ley 100 de 1993 establece dos regímenes contributivos para acceder a la pensión de

10 Para mayor desarrollo, véase: Arévalo, D. La protección del adulto mayor: entre la dádiva y el derecho. Crecimiento, equidad y ciudadanía. Hacia un nuevo sistema de protección social. Centro de Investigaciones para el Desarrollo - Universidad Nacional de Colombia, 2006, pp. 283-320; RodríGUEZ SALAZAR, Ó. El liberalismo radical y el sistema de pensiones. En La falacia neoliberal. Críticas y alternativas. D. I. Restrepo Botero (ed.). Bogotá: Universidad Nacional de Colombia, vol. 1, 2003, 323-346; Reformas pensionales. Conmoción interior y reformas laboral, pensional, política, tributaria, judicial y educativa, Universidad Nacional, vol. 1, 2002, 107-113; LóPEZ VILlEGas, E. Seguridad social: teoría crítica, Universidad de Medellín, 2011.

11 Los derechos pensionales se creaban por diferentes autoridades o por los mismos particulares; se dirigían a grupos de trabajadores específicos, por lo que no era un derecho uniforme; no existía la obligación, a cargo de los responsables del pago, de realizar las reservas adecuadas; en algunos casos sólo se causaba la obligación a cargo de un empleador después de que se hubiera trabajado por un número de años determinado, con lo cual se generaban incentivos para terminar las relaciones laborales anticipadamente; entre otros aspectos. 
vejez, entre los cuales pueden escoger libremente los afiliados: uno privado de ahorro en cuentas individuales (RAIS) y otro público de prima media (RPM).

El primero es administrado por fondos de pensiones privados y consiste en el ahorro obligatorio en cuentas individuales de las personas con ingresos, que se suma en el largo plazo a los rendimientos que dicho ahorro genera, para conformar al final de la vida laboral un capital mínimo necesario para disfrutar de una mesada pensional de por lo menos un salario mínimo mensual.

El segundo es administrado por el Estado y, aunque también se alimenta de las contribuciones obligatorias que realizan las personas con ingresos superiores a un salario mínimo mensual, no conforma cuentas individuales, realizándose el pago de las mesadas pensionales con los recursos generales del sistema, los cuales se componen no solo de las cotizaciones de los trabajadores aún activos, sino también de los recursos que el Presupuesto General de la Nación transfiere para completar el saldo requerido para cumplir las obligaciones totales del sistema.

En el Régimen de Prima Media con Prestación Definida, la mesada pensional que recibe cada persona no depende de cuánto se haya ahorrado, como en el primer caso, sino del tiempo cotizado y del salario devengado durante la última década de cotizaciones -para la mayoría de los casos-. Así, la mesada pensional mensual que arroja esta fórmula es mayor de la que resultaría de aplicar el cálculo sobre lo verdaderamente ahorrado, por lo que en el tiempo cada mesada debe ser "completada" por el mismo sistema, es decir, debe ser subsidiada con los recursos de las cotizaciones de quienes no se han pensionado y con recursos del Presupuesto General de la Nación.

Por lo anterior, en este régimen existe un subsidio implícito del Estado en cada mesada pensional, puesto que el monto final de todas las mesadas pensionales que se le pagan a un pensionado es superior a lo que este alcanzó a aportar al sistema a lo largo de su vida como cotizante ${ }^{12}$. Es decir, en el régimen "público" (RPM con Prestación Definida), el Estado distribuye los

12 Para comprender mejor la existencia y funcionamiento del subsidio implícito en las mesadas pensionales del RPM, véase: NieTo RAmOs, A. El efecto de las pensiones sobre la desigualdad de ingresos en Colombia. En Documentos CEDE. Edición Electrónica. Bogotá: Universidad de los Andes, 2014, que explica el subsidio implícito de la siguiente manera: "Existen diversas explicaciones a la existencia de estos subsidios pensionales. Montenegro et al. (2013b), por ejemplo, analiza y cuantifica los subsidios pensionales basados en las historias laborales de los afiliados al RAIs y destaca dos causantes centrales; primero, la desactualización de los parámetros que se usan en el RPM para la estimación de las mesadas pensionales, fundamentalmente el envejecimiento de la población colombiana; y segundo, el hecho de considerar sólo los últimos 10 años de historia laboral de los trabajadores como referencia para el cálculo del Ingreso Base de Liquidación. Para Montenegro et al. (2013b), esta consideración se hace nociva pues ignora la tendencia creciente que tienen los salarios de los trabajadores, especialmente los de ingresos altos, en los últimos diez años de su etapa laboral. De aquí, que los subsidios pensionales sean significativamente más altos en los trabajadores de altos salarios. Adicionalmente a los dos puntos anteriores, Montenegro y Rivas (2005) destacan los esfuerzos que realizan algunos trabajadores 
recursos públicos escasos para la garantía del derecho a la pensión, entre las personas con ingresos entre uno y veinticinco salarios mínimos mensuales.

Mientras tanto, para las personas con ingresos inferiores a un salario mínimo mensual el sistema no establece ningún tipo de protección pensional, sino mecanismos que implican incentivos al ahorro ${ }^{13}$, subsidios $^{14} \mathrm{o}$ asistencia social ${ }^{15}$.

Debe resaltarse el hecho de que los esquemas existentes que implican el disfrute de beneficios sin necesidad de realizar cotizaciones son externos o ajenos al sistema pensional, pues, a diferencia de lo que ocurre en el caso de los derechos, su realización depende de circunstancias económicas o políticas, por lo que son beneficios que pueden obtenerse o perderse de acuerdo con las mismas. Por ello, al describir los esquemas no contributivos actuales, el Banco Mundial asegura que los mismos "han tenido una cobertura creciente

para aumentar sus ingresos en la etapa final del su ciclo laboral, en aras de que el cálculo del IBL sea más alto y por consiguiente también su pensión" (Nieto Ramos, 2014, 35).

13 En el Acto Legislativo 01 de 2005, entre otros importantes cambios, se incluyeron los denominados Beneficios Económicos Periódicos (BEPS), los cuales fueron desarrollados constitucionalmente como un mecanismo para entregar mesadas no pensionales a quienes quedaran por fuera del sistema pensional: "Ninguna pensión podrá ser inferior al salario mínimo legal mensual vigente. Sin embargo, la ley podrá determinar los casos en que se puedan conceder beneficios económicos periódicos inferiores al salario mínimo, a personas de escasos recursos que no cumplan con las condiciones requeridas para tener derecho a una pensión". La Ley 1151 de 2007 (Plan Nacional de Desarrollo) estableció que el Gobierno Nacional reglamentaría estas mesadas no pensionales y que las mismas serían administradas por Colpensiones. Pero al año siguiente, mediante una ley relacionada con asuntos financieros, de seguros y del mercado de valores Acto Legislativo 01 de 2005, a saber, la Ley 1328 de 2009, se definieron las reglas generales de carácter legal para la reglamentación de los BEPs: están dirigidos a personas de escasos recursos que ahorren en un mecanismo especial diseñado por el Gobierno Nacional; sólo pueden ser otorgados una vez cumplida la edad de pensión; deben otorgarse con cargo a los recursos del Fondo de Solidaridad Pensional; la mesada no pensional no puede ser igual o superior a un salario mínimo, y el incentivo consiste en un subsidio que se suma al capital individual de acuerdo con el monto ahorrado.

14 La Ley 100 estableció el Fondo de Solidaridad Pensional (FSP), dirigido a la protección de la población de más escasos recursos, el cual completaría la cotización de aquellas personas que no tuvieran suficientes recursos para cotizar al Sistema General de Pensiones (SGP) sobre la base mínima. La Ley 797 de 2003 incluyó la financiación de un subsidio económico con cargo a este Fondo, destinado a la protección de las personas mayores (desde tres años menos de la edad de pensión del SGP en adelante) en estado de indigencia o de pobreza extrema.

15 A lo largo del texto se resaltará la diferencia entre la asistencia pública o social, frente a los derechos en general y al derecho a la seguridad social en particular. Históricamente esta diferencia encuentra sentido en el tránsito constitucional de 1991, momento en el cual la nueva Carta Política superó la protección existente a la "asistencia pública", para entrar a reconocer y proteger un derecho a la seguridad social. Como lo explica Muñoz Segura: "hay un vértice común en todas las propuestas [presentadas en la Asamblea Nacional Constituyente]: hay que reconocer la existencia de un derecho y por ello la protección no puede depender de la voluntad de quien la otorga. Es decir que las discusiones y la posterior consagración del derecho generaron la apertura del discurso de la asistencia pública para dar lugar a la seguridad social para todos los ciudadanos" $(2012,59)$. 
y vinculada [...] a la disponibilidad de recursos presupuestarios" (Rofman, Apella, \& Vezza, 2013).

En este sentido, la protección pensional propiamente dicha del modelo establecido por el legislador desde la Ley 100 de 1993 implica que en Colombia sólo tienen pensiones quienes estén en capacidad de contribuir al sistema, en cualquiera de los dos regímenes, por un periodo de tiempo aproximado de veinticinco años; mientras que las personas de la tercera edad sin ingresos y que no realizaron los aportes necesarios no tienen derecho a la pensión, sino sólo los derivados de la asistencia social y la garantía reforzada de los derechos de esta población, como la vivienda y la alimentación.

\section{ii. La jurisprudencia constitucional sobre el derecho a la pensión en sede de constitucionalidad}

De acuerdo con lo explicado, el modelo pensional establecido por el legislador para la protección del derecho a la pensión no lo desarrolla como un DESC, pues excluye a la población más vulnerable y distribuye los recursos escasos para garantizar el derecho entre las personas de mayores ingresos. Así las cosas, ante lo que pareciera una evidente contradicción constitucional del legislador, es preciso preguntarse qué ha dicho la Corte Constitucional en sede de constitucionalidad sobre este modelo.

Un análisis detallado de las sentencias de constitucionalidad de la Corte Constituciona $1{ }^{16}$ permite identificar que de un universo aproximado de 206 sentencias de constitucionalidad referidas al tema pensional, sólo 83 se ocupan de los asuntos relacionados directamente con el modelo pensional de la Ley 100 de 1993 -excluyendo algunas sentencias referidas a temas de trámite o en las que se realizaban simples reiteraciones-. De esas 83 sentencias, únicamente fue posible identificar seis en las que, en razón del tema de decisión o de los argumentos de la demanda, la Corte parece haber tenido la oportunidad de manifestarse sobre la constitucionalidad del modelo pensional, y sin embargo, sólo tres de ellas se ocuparon de asuntos de fondo, a saber, las sentencias C-408 de 1994, C-086 de 2002 y C-243 de 2006.

Teniendo en cuenta los tres fallos identificados en el párrafo anterior, pueden diferenciarse dos momentos en la jurisprudencia de la Corte Constitucional en relación con el derecho a la pensión: (i) el de la jurisprudencia inicial (1992-1994), que defendía un concepto retardatario del derecho a

16 Si bien existen importantes desarrollos en la jurisprudencia producida por la Corte en sede de tutela y de unificación, en este acápite sólo se estudian la sentencias de constitucionalidad, pues el objeto de este es determinar si, con base en las exigencias constitucionales que se imponen al legislador para el desarrollo del derecho a la pensión, la Corte ha objetado de alguna manera o por lo menos identificado el hecho de que el derecho no se proteja a la población sin ingresos. 
la pensión, como un derecho derivado del derecho al trabajo, negando por tanto sus características como DESC, de las cuales gozaba incluso antes de la Constitución de 1991; y, (ii) el periodo posterior a la Ley 100 de 1993, en el que se ubican las tres sentencias identificadas supra, en el cual la Corte se aleja de la concepción meramente laboral, pero avala tácitamente el modelo exclusivamente contributivo establecido por el legislador, el cual también desconoce el derecho a la pensión como DESC.

En las sentencias anteriores a la expedición de la Ley 100 de 1993, el derecho a la pensión fue comprendido principalmente como una derivación del derecho al trabajo y, más específicamente, como una de las formas de retribución a que tiene derecho quien presta un servicio laboral: "El pago de las pensiones, como todo pago de orden laboral, se funda en la idea de retribución por el trabajo de que tratan los artículos 25 y 53 de la Constitución" (Corte Constitucional, Sentencia C-546 de 1992).

En síntesis, para la concepción inicial de la jurisprudencia constitucional, la pensión es el derecho a una mesada mensual a favor de quien ostenta la condición especial de haber sido trabajador. El derecho de los trabajadores a recibir el pago pensional, de acuerdo con la misma sentencia, se produce como una devolución del ahorro forzoso y no como una dádiva del Estado al trabajador.

Hasta este punto, la concepción de simple reintegro presenta dificultades conceptuales graves respecto de lo que se recibe -y se recibía en aquella época- en una mesada pensional: como hemos explicado, buena parte de la mesada es un subsidio que el Estado entrega a personas que, de acuerdo con las reglas de priorización del gasto y el principio de progresividad, no deberían recibirlo. Es decir, la pensión en el RPM no es un simple reintegro del ahorro, sino más bien una compleja distribución de los recursos públicos, los cuales terminan convirtiéndose en un subsidio que el Estado otorga al pensionado en cada mesada pensional.

A pesar de que hasta 1994 la Sentencia C-546 de 1992 es la única que aborda una problemática pensional en sede de constitucionalidad, como veremos, la misma establece unas subreglas de interpretación del derecho a la pensión que serán retomadas posteriormente en diversas providencias de la misma Corte. En este sentido, esta concepción laboralista de las pensiones se mantuvo sin modificaciones importantes hasta 1994, año en el que las sentencias C-012 y C-408 supusieron avances jurisprudenciales en la comprensión constitucional del derecho pensional.

Aunque la Sentencia C-012 de 1994 no es propiamente un manual constitucional sobre el derecho a la pensión, ni se refiere al modelo de la Ley 100 -pues se encontraba demandada una disposición de la Ley 71 de 1988-, resulta interesante para este análisis, en la medida en que marca un punto de partida diferente respecto de la jurisprudencia anterior: en lugar de encuadrar 
el derecho a la pensión como el derecho a un pago laboral o simplemente retributivo del ahorro de un trabajador, parte del derecho a la seguridad social como un presupuesto básico del Estado social de derecho, fundamental por conexidad, que incluye el derecho a la protección de la población frente a ciertos riesgos y eventualidades, entre los cuales se encuentran la enfermedad, la vejez, la invalidez y la muerte. Sin embargo, esta sentencia y la nueva jurisprudencia que pareciera proponer no encuentra desarrollo en las discusiones posteriores sobre el sistema pensional.

Además de este acercamiento al derecho a la pensión, la Corte comienza a definir, en sede de constitucionalidad, asuntos centrales en la comprensión de este derecho, en especial en lo referente a la obligación a cargo de los beneficiaros de cumplir estrictamente con los requisitos de la ley para tener un derecho cierto y no una mera expectativa ${ }^{17}$.

Esta diferenciación no solo será central en lo que sigue en la discusión pensional, sino también en la comprensión del derecho, pues de ella surge una característica especial, consistente en que tal derecho se encuentra sujeto al cumplimiento de unas condiciones mínimas, relacionadas con la edad y el tiempo cotizado, determinantes además del monto que finalmente es reconocido. En este sentido, no se trata, como se había dicho anteriormente, de una simple retribución del ahorro del trabajador o de un pago laboral: es un derecho condicionado, al cual sólo se accede por el esfuerzo del trabajador a lo largo de su vida, y que sólo se consolida con el cumplimiento estricto de las condiciones legales.

Si bien es posible identificar un leve cambio respecto de la comprensión jurisprudencial anterior, es claro que para la Corte el derecho a la pensión continuaba siendo, a pesar de encontrarse enmarcado en el derecho a la seguridad social, un derecho exclusivamente laboral. De hecho, debe recordarse que para esta época los afiliados obligatorios del Sistema General de Pensiones eran aquellas personas vinculadas mediante contrato de trabajo o como servidores públicos, mientras que los contratistas, trabajadores independientes y demás personas con ingresos suficientes para realizar cotizaciones entraban en la categoría de afiliados voluntarios.

Así, el sistema recibió durante diez años de su existencia el aporte casi exclusivo de la población vinculada formalmente al mercado laboral, y fue sólo en el año 2003, mediante la Ley 797, que se incluyó a las demás personas como afiliados obligatorios del Sistema General de Pensiones. En este sentido, fue la misma ley la que realizó esta corrección, al incluir a personas diferentes a los trabajadores formales como afiliados obligatorios, mientras

17 Por ejemplo, establece que "mientras no se reúnan los requisitos legales para obtener derecho a una pensión, tal aspiración constituye apenas una mera posibilidad de adquirirlo; es decir, que mientras el trabajador no cumpla con los requisitos del tiempo de servicio y de la edad, no tiene un derecho cierto, sino una expectativa de derecho a la jubilación”. 
que la jurisprudencia hasta ahora citada avaló los modelos legales sin realizar mayores objeciones a los mismos.

Posteriormente, en la Sentencia C-408 de $1994^{[18]}$, aunque la mayoría de los cargos realizados sobre la Ley 100 se referían a cuestiones de procedimiento, la Corte decide profundizar en la naturaleza del derecho a la seguridad social, con miras a establecer si el mismo debía ser objeto del trámite especial de ley estatutaria al ser regulado por el legislador. En dicho análisis concluye que es un derecho de segunda generación, teniendo en cuenta no sólo su ubicación en la carta de derechos de la Constitución Política sino también sus características como DESC, especialmente las relacionadas con el mandato de progresividad, con las restricciones impuestas por las limitaciones fiscales y con la necesidad de su desarrollo legal y administrativo.

El derecho a la pensión se entiende en términos generales como un derecho incluido dentro de las prestaciones propias de la seguridad social, que estaría sujeto por tanto a sus mismas características. Así mismo, sería visto como un derecho que no se desprende necesariamente del derecho al trabajo, sino como una prestación a la que podría tener derecho cualquier colombiano.

En este sentido, por lo menos en lo que a la seguridad social se refiere, la Corte reconoce una independencia parcial respecto de los asuntos laborales. Sin embargo, existe una referencia general a los "derechos onerosos", indicando que en la mayoría de los casos gozan de esta característica, sin que la misma se haya desarrollado en la sentencia, pero dentro de la cual se podría entender incluido el derecho a la pensión como un derecho meramente oneroso. Bajo este punto de vista, existiría el derecho a la pensión para aquellas personas con capacidad de pago, mientras que aquellas sin dicha capacidad tendrían derecho a la asistencia pública. Por ello, aunque este escenario pareciera acercar más a la Corte a la concepción del derecho a la pensión como un verdadero DESC, termina alejándose de la misma al aceptar su existencia como derecho exclusivamente contributivo.

A pesar de estos sutiles y pequeños avances, la jurisprudencia posterior continuó reiterando las líneas jurisprudenciales sobre el derecho a la pensión como un derecho de orden laboral ${ }^{19}$. Por ejemplo, en la Sentencia C-126 de 1995 la Corte reconoce sin objeción que la Ley 100, en lo referente al sistema de pensiones, se ocupa exclusivamente de la población trabajadora, reconocimiento que implica que el cumplimiento de los mandatos de garantía de la seguridad social y del principio de progresividad no está completo: sólo se cubre verdaderamente a aquella población vinculada formalmente al mercado laboral.

18 Primera de las tres sentencias identificadas en el análisis como relevante, por haberse alegado o abordado asuntos relacionados con el concepto, naturaleza o desarrollo del derecho a la pensión.

19 Ver, p. ej., Corte Constitucional, sentencias C-126 de 1995, C-155 y C-179 de 1997. 
La segunda de las tres sentencias identificadas, esto es, la C-086 de 2002, resolvía una demanda de inconstitucionalidad dirigida concretamente contra el Régimen de Ahorro Individual, demandado por considerar que el mismo, dada su característica predominante de individualidad, resultaba contrario al principio de solidaridad, propio de los regímenes pensionales y del Sistema General de Seguridad Social.

Teniendo en cuenta la amplitud de los cargos manifestados por el actor contra la Ley 100, la Corte contaba con un amplio margen de decisión, pues se ponía en entredicho uno de los pilares fundamentales de dicha ley, el RAIS, régimen que constituía la única opción viable en la propuesta inicialmente presentada por el Gobierno Nacional. En esta medida, la demanda, a diferencia de las demás revisadas, ofrecía una oportunidad importante para la Corte en la revisión de la estructura y el modelo general del Sistema General de Pensiones en el marco de los DESC.

En concreto, además de realizar algunas consideraciones descriptivas de los dos regímenes pensionales, la Corte indicó que la exigencia contributiva del modelo pensional se constituía en "expresión directa del principio de solidaridad". Es decir, casi una década después de aprobada la Ley 100 de 1993, la Corte no sólo no encuentra problemas en que el derecho a la pensión continúe siendo un derecho exclusivamente contributivo, sino que estima que dicha característica demuestra el respeto por el principio solidario inmerso en el Sistema General de Seguridad Social.

Todo lo anterior, en el marco de la libertad de configuración del legislador, el cual, de acuerdo con esta posición de la Corte, no tendría ninguna obligación de cobertura respecto de las personas sin capacidad de pago. En otras palabras, el derecho a la pensión es tal solamente para quienes tienen capacidad de pago. Contrario sensu, quienes no tienen tal capacidad sólo tienen derecho a la asistencia estatal a la tercera edad, cuando cumplen con los requisitos de pobreza e indigencia extrema.

Finalmente, mediante la Sentencia C-243 de 2006, la Corte estudia la naturaleza y objeto del Fondo de Solidaridad Pensional ${ }^{20}$, frente a una demanda de inconstitucionalidad dirigida específicamente contra la preferencia establecida en la norma por administradores del sector solidario.

Aunque el tema de decisión en este caso se encontraba más acotado, la Corte realizó una revisión amplia de la naturaleza y objeto del Fondo a la luz de los principios constitucionales del Estado social de derecho, análisis que permite comprender la posición de la Corte en uno de los puntos clave

20 Como se explicó más arriba, el Fondo de Solidaridad Pensional fue creado por la Ley 100 y reformado por la Ley 797, con dos finalidades: (i) otorgar subsidios a la cotización (completar la cotización) de aquellas personas con ingresos inferiores a un salario mínimo que quisieran afiliarse y aportar al sistema, y (ii) otorgar sumas de dinero periódicas -no pensionales, sino asistenciales- a las personas de la tercera edad en situación de pobreza o indigencia extrema. 
del sistema pensional: la utilización de los recursos provenientes de las cotizaciones para la asistencia social a favor de aquellas personas excluidas de dicho sistema o de quienes no alcanzan a pagar la totalidad de la cotización por sus bajos ingresos. Es decir, el uso de recursos que el sistema de pensiones obtiene de las cotizaciones de sus afiliados, para el pago de subsidios o dádivas a las personas que el mismo sistema excluye.

En este caso, aunque la Corte parte del supuesto de que la seguridad social es un "derecho irrenunciable que se garantiza a todos los habitantes", posteriormente reitera, en por lo menos seis ocasiones en el texto de la providencia, que el legislador cuenta con un amplio margen de configuración del derecho, lo cual no sería reprochable si la Corte se ocupara de explicar cuál es el marco constitucional mínimo al que debería sujetarse ese amplio margen de configuración.

Por ejemplo, si se indicara cuál es la diferencia constitucional entre la seguridad social y la asistencia pública, entre un subsidio y una pensión, o entre la liberalidad política coyuntural y los derechos como obligaciones del Estado frente a los ciudadanos, podría hablarse de un amplio margen de configuración enmarcado en límites constitucionales generales. En otras palabras, debería explicarse cómo resulta coherente el hecho de que la seguridad social sea un "derecho irrenunciable que se garantiza a todos los habitantes" y el que que solamente las personas con capacidad de pago tengan derecho a la pensión en sentido estricto.

Este fallo fue la tercera y última opción que tuvo la Corte Constitucional para realizar un análisis más profundo del derecho a la pensión como DESC, y fue, al igual que en los demás casos citados, evidentemente desperdiciada. Posteriormente, en por lo menos 27 sentencias $^{21}$, la Corte mantuvo una posición similar, defendiendo el modelo contributivo pensional establecido por la Ley 100 de 1993.

\section{LOS PROBLEMAS CONSTITUCIONALES DEL SISTEMA DE PENSIONES}

A partir de las conclusiones parciales explicadas en cada uno de los acápites anteriores, a continuación, en primer lugar, se busca demostrar la inconstitucionalidad del régimen general de pensiones por excluir a las personas sin ingresos o con ingresos inferiores a un salario mínimo, así como por destinar los recursos públicos necesarios para la protección del derecho a la pensión de vejez, a la población de mayores ingresos. En segundo lugar, se formula una propuesta sobre las reformas o acciones tendientes a la superación de la

21 C-530, C-896, C-989 y C-1043 de 2006; C-100, C-294 y C-625 de 2007; C-032, C-336, C-859, C-1035 y C-1196 de 2008; C-259, C-428, C-556 y C-727 de 2009; C-240 y C-529 de 2010; C-090 y C-228 de 2011; C-589 y C-1057 de 2012; C-102, C-110, C-525, C-613 y C-914 de 2013. 
problemática argumentada, con base en los requisitos constitucionales para el desarrollo y protección de los DESC.

\section{i. La pensión como derecho no contributivo}

En el SIDH existen tratados internacionales sobre derechos humanos ratificados por Colombia que establecen y protegen los DESC, indicando que los mismos deben ser garantizados progresivamente por los Estados ${ }^{22}$.

Este mandato de progresividad implica que el Estado debe reconocer paulatinamente los DESC, por lo que su realización absoluta no puede ser exigida de manera inmediata. Pero, al mismo tiempo, los DESC cuentan con un contenido esencial que el Estado debe proteger en todo momento, relacionado con los derechos mínimos de subsistencia, la necesidades básicas, el mínimo vital y la dignidad humana ${ }^{23}$. Así, el mandato de progresividad implica también que los recursos escasos se prioricen en la población que más lo necesite o en la que verdaderamente requiera de la protección que confiere un DESC determinado.

El derecho a la pensión ha sido reconocido como un DESC, tanto por el texto de la Constitución Política como por los tratados internacionales sobre derechos humanos ratificados por Colombia. Dicho reconocimiento supone, entre otras cosas: que la Constitución exige al Estado destinar recursos para la protección progresiva de este derecho; que la protección progresiva debe priorizar los recursos escasos en la población que más lo necesita o que verdaderamente lo necesita, y que, dado que es un derecho, difiere de la mera asistencia o ayuda social $^{24}$, por lo que no depende de la voluntad política coyuntural.

22 Convención Americana sobre Derechos Humanos (CADH), Carta de la oEA y Protocolo Adicional a la CADH sobre Derechos Económicos, Sociales y Culturales.

23 En la Sentencia C-251 de 1997, la Corte indica que existe un contenido mínimo de los DESC que es de aplicación y exigibilidad inmediata, relacionado con estos conceptos, especialmente con el mínimo vital. Así, además de las otras formas en que se explica el principio de priorización en la primera parte de este documento (supra I), el mismo puede ser explicado a partir del concepto de contenido mínimo o esencial de los DESC: así como cualquier prestación propia de un DESC que se requiera para la subsistencia mínima (como la alimentación), debe ser proveída de forma inmediata por el Estado, cualquier desarrollo de los DESC debe realizarse respecto de la población que más lo requiera. Las escasez de los recursos para la protección de los DESC implica que los mismos deben cubrir progresivamente a la población que más lo necesite o que verdaderamente lo requiera.

24 Esta diferencia entre la asistencia social y los derechos se centra en el hecho de que los derechos, por su naturaleza, consagración y protección constitucional, no dependen de la voluntad política de los gobiernos, sino que por sus características se consolidan como responsabilidades concretas a cargo del Estado, que para el caso de los DESC debe cumplirlos progresivamente. Por su parte, los programas de asistencia o ayuda social implican un complemento a los mecanismos para hacer efectivo el goce de los derechos, pero dependen de las políticas públicas de cada gobierno, de la priorización de recursos y de los intereses políticos. Es decir, bajo esta perspec- 
El sistema pensional colombiano es un sistema exclusivamente contributivo. Esto quiere decir que sólo tienen derecho a acceder a una pensión de vejez quienes cumplen con un ahorro mínimo o con un tiempo mínimo de cotización. Al mismo tiempo, esta característica básica del sistema implica que las personas con ingresos inferiores a un salario mínimo mensual o sin ingresos se encuentran excluidas del sistema. Este grupo poblacional, cuando se encontraría en edad para pensionarse, sólo recibe subsidios o dádivas propias de la asistencia social, como alimentación o albergue eventual.

Dadas las anteriores características, el sistema pensional colombiano, para la protección del derecho a la pensión de vejez, no cumple con ninguno de los requisitos constitucionales señalados: no destina recursos para la protección progresiva y priorizada de la población más necesitada, y no se diferencia, respecto de esta población, de la asistencia social.

Esta exclusión de las personas de menores recursos del sistema pensional implica una omisión constitucional relativa ${ }^{25}$ : el legislador podía regular el derecho a la pensión creando sistemas basados en la contribución de los usuarios, pero no podía considerar que esta regulación representaba toda la protección exigida constitucionalmente al Estado respecto de este derecho. En cuanto DESC, el derecho a la pensión de vejez debe ser protegido, en su contenido mínimo constitucional, a la población sin recursos de la tercera edad. No hacerlo, desconoce las obligaciones constitucionales del Estado en la protección mínima de los DESC.

En otras palabras, si la Constitución exige que el derecho a la pensión sea reconocido progresivamente, y en ejecución de ese mandato el Estado establece una regulación que excluye sin justificación a las personas sin ingresos, se configura una responsabilidad del mismo por vulnerar el derecho social a causa de la omisión parcial en su regulación. De acuerdo con los criterios definidos por la Corte, en este caso se presentarían todos los supuestos en los que podría entenderse que el legislador actúa en contra de la Constitución por omisión relativa:

tiva, la asistencia pública social en sentido estricto es eventual, no es de exigibilidad inmediata y no genera a favor de la persona que la recibe un derecho irrenunciable e inmejorable. Por ello, Arenas Monsalve, al referirse a la nueva concepción de la seguridad social en la Constitución de 1991, indica que "la seguridad social, como ideal de protección de toda la población contra las necesidades colectivas, constituye la máxima concepción de la protección social como derecho, pues ahí desaparece toda noción de asistencia pública como beneficio gratuito y con carácter de dádiva, para transformarse en el derecho humano fundamental" $(1992,48)$.

25 De acuerdo con la Corte, "La omisión legislativa relativa tiene lugar cuando el legislador 'al regular o construir una institución omite una condición o un ingrediente que, de acuerdo con la Constitución, sería exigencia esencial para armonizar con ella'" (Corte Constitucional, Sentencia C-767 de 2004). 
(i) cuando expide una ley que si bien desarrolla un deber impuesto por la Constitución, favorece a ciertos sectores y perjudica a otros; (ii) cuando adopta un precepto que corresponde a una obligación constitucional, pero excluye expresa o tácitamente a un grupo de ciudadanos de los beneficios que otorga a los demás; y (iii) cuando al regular una institución omite una condición o un elemento esencial exigido por la Constitución (Corte Constitucional, Sentencia C-767 de 2004).

De acuerdo con Arango Rivadeneira, cabe entender la omisión parcial como un acción incompleta del Estado que puede violar los derechos de las personas, al tratar de manera diferente, sin justificación, a quienes deberían ser tratados igual, o bien al no realizar diferencias entre quienes debía realizarlas. En este sentido, el juicio de omisión legislativa es un juicio de igualdad, pero además de diligencia: "una omisión (acción negativa) no es fácilmente perceptible y estimable como causa de vulneración de un derecho fundamental. Por esto, para comprobar la constitucionalidad de una omisión estatal parcial, esta se juzga con respecto a una acción diligente" (2012, pp. 186-190).

De hecho, para la Corte, dentro de los requisitos argumentativos que debe cumplir una demanda de inconstitucionalidad por omisión legislativa relativa, se encuentran por lo menos dos requisitos relacionados con la vulneración del principio de igualdad. Veamos:

i) la existencia de una norma frente a la cual se predique la omisión; ii) la norma acusada debe excluir un ingrediente, condición normativa o consecuencia jurídica que a partir de un análisis inicial o de una visión global de su contenido, permita concluir que su consagración normativa resulta esencial e indispensable para armonizar el texto legal con los mandatos de la Carta; iii) que la omisión en tal norma excluya de sus consecuencias aquellos casos que, por ser asimilables, deberían subsumirse dentro de su presupuesto fáctico; iv) que dicha exclusión no obedezca a una razón objetiva y suficiente; v) que al carecer de una razón objetiva y suficiente, la omisión produzca una desigualdad injustificada entre los casos que están y los que no están sujetos a las consecuencias previstas por la norma $\mathrm{y}$, vi) que la omisión implique el incumplimiento de un deber constitucional del legislador (Corte Constitucional, Sentencia C-767 de 2004, resaltado fuera de texto).

Así, el sistema pensional definido por el legislador excluye de sus consecuencias a las personas carentes de ingresos ${ }^{26}$, sin tener para ello una razón objetiva y suficiente, generando una desigualdad injustificada entre las personas sin capacidad de pago y las que sí la tienen, omisión con la que incumple el deber constitucional de protección del derecho a la pensión.

26 Los Beps o los subsidios del Fondo de Solidaridad Pensional, no pueden entenderse como beneficios pensionales. Antes que de mecanismos para la protección del derecho a la pensión, se trata de beneficios estatales propios de la asistencia pública para quienes no pudieron acceder al derecho (infra). 
Por otra parte, debe observarse que el sistema no sólo excluye de su regulación a la población sin ingresos, sino que en el RPM destina a la protección de la población de mayores ingresos los recursos públicos escasos necesarios para la protección del derecho a la pensión de vejez a toda la población. Lo anterior, dado que en razón de la fórmula legal con la que se calcula la mesada pensional, esta resulta mayor a lo que se podría pagar con el dinero cotizado, por lo que es necesario que el Estado "complete" los recursos faltantes de cada mesada pensional. Esto significa que el RPM subsidia a personas que tienen capacidad de pago y no protege a aquellas que no la tienen.

Por ello, esta característica, además de agravar y acentuar el caso de desigualdad explicado en la omisión legislativa, implica una inconstitucionalidad directa del RPM, pues el mismo desconoce la prohibición de regresividad del sistema tributario mediante instrumentos irrazonables o que desconozcan el mínimo vital y el mandato de priorización implícito en el principio de progresividad de los DESC $^{27}$.

En resumen, el Sistema General de Pensiones contiene una omisión legislativa relativa al excluir a la población de menores ingresos de la protección de un DESC; y en particular, contiene un régimen que es inconstitucional por el hecho de financiarse con los recursos públicos escasos que deberían dirigirse a la protección de la población más vulnerable.

Si bien no resulta procedente ni conveniente que la Corte Constitucional defina el modelo que se debería seguir -que, como veremos más adelante, puede adoptar varias formas-, sí resultaba exigible, desde el estudio de constitucionalidad de las normas legales pensionales, la identificación de la obligación a cargo del legislador de establecer un sistema pensional que reconociera el derecho a la pensión para las personas sin ingresos.

\section{ii. Una regulación adecuada del derecho a la pensión de vejez}

Una comprensión correcta de los derechos que se derivan del mandato constitucional a la seguridad social, en lo que respecta a la protección a la vejez, diferenciaría claramente, como lo hacen otros sistemas en el mundo ${ }^{28}$ y lo recomiendan el Banco Mundial y el Banco Interamericano de Desarrollo ${ }^{29}$, entre "pilares" (Holzmann \& Richard, 2006, p. 101) (Bosch, Melguizo, \&

27 Ver, p. ej., Sentencia C-100 de 2014.

28 Por ejemplo, en Bolivia, todo ciudadano mayor de 60 años, si es mujer, y de 65, si es hombre, tiene derecho a recibir una "renta dignidad", la cual es universal, es decir, no está condicionada a los ingresos del individuo, y puede percibirse con la pensión contributiva. Esta renta, que se configura como una pensión no contributiva, se ve disminuida en un $25 \%$ para quienes obtienen el derecho a una pensión contributiva.

29 Mientras el Banco Mundial se refiere a la necesidad de contar con diferentes pilares, el Banco Interamericano de Desarrollo propone la implementación de una "pensión básica universal antipobreza". 
Pagés, 2013,p. 145). Esto quiere decir que para garantizar la protección a la vejez, en el marco de la seguridad social y de algunos riesgos como la invalidez o la muerte, el Estado debería diferenciar entre las personas con capacidad de pago y las personas de escasos recursos. No hacerlo, como hemos visto, implica negar el derecho para el segundo grupo, en especial si el sistema se establece exclusivamente para aquellas personas con capacidad de pago.

El sistema de pilares implica que existe un nivel "básico", el cual reconoce derechos pensionales a las personas que, por no poseer medios económicos, no accedieron a pensiones a través de los aportes al sistema de seguridad social. Dicho pilar básico conlleva el reconocimiento de que el derecho a la pensión es un DESC y que su contenido mínimo exige que las personas en la tercera edad sin ingresos deban ser protegidas progresivamente en virtud de este derecho.

Ni los Beps ni el Fondo de Solidaridad Pensional pueden ser considerados como mecanismos del pilar básico, pues ambos son programas que podrían denominarse "extrapensionales", en el sentido de que no implican el otorgamiento de una pensión, sino un apoyo económico para acceder a la misma o un apoyo económico para quien no pudo cumplir los requisitos para obtenerla. Como se explicó antes, a diferencia de los derechos, este tipo de programas sociales son mecanismos de asistencia pública, antes que la ejecución de programas para la garantía de derechos.

En Colombia, de acuerdo con lo explicado, sería necesario regular el pilar básico, estableciendo las condiciones bajo las cuales una persona que no hubiere realizado cotizaciones suficientes -o ninguna cotización- en el pilar contributivo, podría acceder a una mesada pensional, la cual, adicionalmente, tendría que ser inferior al salario mínimo ${ }^{30}$, para evitar los incentivos a no cotizar que se generarían por obtener iguales prestaciones en uno y otro pilar.

30 Desde la Ley 100 de 1993 las pensiones se ataron al salario mínimo -arts. 35, 40 y 48-, y a partir de la misma se estableció por la Corte Constitucional el concepto de "pensión mínima" -Sentencia C-387 de 1994-, el cual fue ampliado indicando que en aquellos casos en que el ajuste del salario mínimo fuera inferior al IPC, las pensiones de salario mínimo deberían incrementase con base en este último índice. Esta concepción fue repetida y petrificada en la Constitución Política, la cual fue enmendada mediante el Acto Legislativo 01 de 2005, el cual estableció expresamente: "Ninguna pensión podrá ser inferior al salario mínimo legal mensual vigente”. Esta disposición, además de limitar las decisiones disponibles de política pública para ampliar la cobertura en las pensiones contributivas -especialmente en el régimen de ahorro individual-, también pareciera contraria a la propuesta de tener un pilar básico que sea inferior al salario mínimo. Esto, especialmente porque el artículo 48 superior, en el mismo inciso en que establece esta prohibición, reconoce implícitamente que el derecho a la pensión es exclusivamente contributivo, al indicar: "Sin embargo, la ley podrá determinar los casos en que se puedan conceder beneficios económicos periódicos inferiores al salario mínimo, a personas de escasos recursos que no cumplan con las condiciones requeridas para tener derecho a una pensión" (resaltado fuera del texto original). Por esto, es necesario contar con una estrategia que permita revertir los efectos de esta disposición, en cuanto a la interpretación del derecho a la pensión como un derecho meramente contributivo, como la posibilidad de promover una interpretación 
Sin embargo, este cambio no sería suficiente. Mientras el RPM continúe existiendo con las condiciones actuales, el mismo requerirá de recursos del Presupuesto General de la Nación para su financiación. Estos recursos públicos se destinarán a financiar las pensiones de las personas con ingresos, lo cual irá en detrimento de la financiación del pilar básico (personas más vulnerables, de bajos o nulos ingresos) y, con ello, de los mandatos constitucionales referidos a la progresividad de los DESC, la prohibición de regresividad tributaria y la priorización del gasto público ${ }^{31}$.

Por lo anterior, la creación del pilar básico progresivo exige la modificación correlativa del pilar contributivo: dado que las personas que se encuentran afiliadas en la actualidad a dicho régimen ya cuentan con una expectativa que puede considerarse constitucionalmente protegida, el RPM debería cerrarse para nuevos afiliados ${ }^{32}$. Con ello se garantizaría que no existirán más subsidios que los actualmente calculados para la población afiliada, pudiendo destinarse los recursos públicos a la población más vulnerable en el pilar no contributivo.

Cualquier modelo que se estructure a partir de esta decisión, debería considerar una destinación casi exclusiva de recursos públicos a la población de la tercera edad sin ingresos, así como un pilar contributivo que puede combinar sistemas públicos y privados, pero evitando la desviación de recursos públicos hacia las personas de mayores ingresos.

Esto se podría lograr por medio de un sistema que solamente subsidie el ingreso correspondiente a los dos primeros salarios mínimos a través de un RPM, y que a partir de allí se combine con un esquema de ahorro individual, en el que se ahorrarían los ingresos superiores a la base de dos salarios mínimos y que reconocería una mesada pensional de renta vitalicia. Con

de la misma que determine que la prohibición de tener pensiones inferiores al salario mínimo sólo opere para pensiones contributivas. Todo esto, a pesar de la experiencia internacional, que en la actualidad discute formas para ampliar los pilares básicos, como en España, donde se propone incrementar 'el umbral máximo de rentas establecidas para el acceso a las pensiones no contributivas y, en consecuencia, su cuantía para llegar a situarse en el entorno del SMI, sólo algo por debajo de las pensiones mínimas contributivas"” (Suárez Corujo, 2014, 330).

31 Los traslados desde el régimen de ahorro individual (privado) al régimen de prima media (público) van en aumento e implican que el Estado debe asumir cada vez más pensionados, los cuales ahorran la mayor parte de su vida en el régimen privado y van a pensionarse al régimen público, donde obtienen los subsidios implícitos de la mesada pensional. Esto supone que la carga fiscal futura de las pensiones en el RPM sea cada vez mayor y que los recursos públicos necesarios para la financiación de este régimen cada año aumenten, con lo cual se agrava el desvío de los recursos escasos necesarios para la protección de la población más vulnerable en el pilar básico.

32 Por efecto de las cotizaciones por nuevas afiliaciones y por los recursos que recibe el RPM anualmente por traslados desde el Régimen de Ahorro Individual, el cierre inmediato ocasiona un efecto fiscal tan importante que el mismo no podría realizarse de forma inmediata. Por ejemplo, de acuerdo con cifras del Ministerio de Hacienda y Crédito Público, como efecto de los traslados que se efectuaron en el año 2013, el RPM recibió 3,6 billones de pesos (Minhacienda, 2013). 
ello se disminuiría el efecto inequitativo que implica el esquema de prima media actual, y se podrían redirigir los recursos para el pago de pensiones no contributivas a la población que más lo requiera.

\section{REFERENCIAS}

Arango Rivadeneira, R. (2012). El concepto de derechos sociales fundamentales. Bogotá: Legis.

Arenas Monsalve, G. (Mayo de 1992). El trabajo y la seguridad social en la constitución de 1991. Revista de Derecho Privado, 31-77.

Arévalo, D. (2006). La protección del adulto mayor: entre la dádiva y el derecho. Crecimiento, equidad y ciudadanía. Hacia un nuevo sistema de protección social, 283-320.

Arévalo, D. (2009). Muchas acciones y una solución distante. Mecanismos gubernamentales de protección social en Bogotá, 1930-1945. Historia Crítica 1(37), 166-186.

Banco Mundial (1994). Averting the Old Crisis. Oxford University Press.

Bosch, M.; Melguizo, Á. y Pagés, C. (2013). Mejores pensiones, mejores trabajos. Hacia la cobertura universal en América Latina y el Caribe (2. ${ }^{a}$ ed.). Banco Interamericano de Desarrollo.

Castillo Cadena, F. (2006). Los principios de progresividad en la cobertura y de sostenibilidad financiera de la seguridad social en el derecho constitucional: una perspectiva desde el análisis económico. Vniversitas, 111-147.

Cepeda Espinosa, M. (2007). Polémicas constitucionales. Bogotá: Legis.

Courtis, C. (2009). El mundo prometido. Escritos sobre derechos sociales y derechos humanos. México: Fontamara.

González Moreno, B. (2002). El Estado Social. Naturaleza jurídica y estructura de los derechos sociales. Madrid: Civitas.

Holzmann, R. y Richard, H. (2006). Soporte del ingreso económico en la vejez en el siglo veintiuno. Banco Mundial - Mayol.

López Villegas, E. (2011). Seguridad social: teoría crítica. Universidad de Medellín.

Llanes, M. y Piraquive, G. (2012). Sistemas pensionales y solidarios de Chile, Irlanda, Polonia, Brasil y Perú. Bogotá: Archivos de Economía - DNP.

Minhacienda (2013). Informe de Seguimiento Fiscal - Movilidad e interacción entre regímenes del Sistema General de Pensiones Colombiano. Bogotá: Ministerio de Hacienda y Crédito Público.

Muñoz Segura, A. (2012). La Constitución de 1991 y la Seguridad Social: el derecho laboral generalizado. Bogotá: Universidad de los Andes, Vicerrectoría de Investigaciones. 
Nieto Ramos, A. (2014). El efecto de las pensiones sobre la desigualdad de ingresos en Colombia. Bogotá: Documento CEDE, Ediciones Uniandes.

Rodríguez Salazar, O. (2003). El liberalismo radical y el sistema de pensiones. La falacia neoliberal. Críticas y alternativas, 323-346.

Rofman, R.; Apella, I. y Vezza, E. (2013). Más allá de las pensiones contributivas. Catorce experiencias en América Latina. Buenos Aires: Banco Mundial.

Romero Villamizar, L. (2013). Los mecanismos de supervisión y garantías de los Derechos Económicos, Sociales y Culturales en el Sistema Europeo de Derechos Humanos y en el Sistema Interamericano de Derechos Humanos. Revista de Derecho Público, 30.

SuÁrez Corujo, B. (2014). Sistema público de pensiones: crisis, reforma y sostenibilidad. Valladolid: Aranzadi.

Sunstein, C. (2010). Acuerdos carentes de una teoría completa en derecho constitucional y otros ensayos. Cali: Universidad ICESI. 